\title{
Assistência pautada nos direitos sexuais e reprodutivos: uma condição para promover a saúde da mulher ${ }^{1}$
}

\author{
Care assistance sustained in sexual and reproductive rights: a condition for promoting women's health
}

Guiadas de asistencia en materia de derechos sexuales y reproductivos: una condición para promover la salud de la mujer

\author{
Danielle Moreira Marques ${ }^{\mathrm{I}}$, Adriana Lemos Pereira ${ }^{\mathrm{II}}$
}

\section{RESUMO}

Os direitos sexuais e reprodutivos constituem parte dos direitos humanos apoiados pelo governo brasileiro e que, por isso, devem ser garantidos a qualquer cidadão. Entretanto, a ação ou omissão de profissionais de saúde no campo da sexualidade e reprodução podem resultar em violação de tais direitos. Este estudo teve como objetivo identificar, a partir dos relatos de puérperas, a violação dos direitos aqui citados. O estudo descritivo foi realizado no mês de julho de 2009 em um Centro Municipal de Saúde, no Rio de Janeiro, com abordagem qualitativa, baseado no relato de vinte mulheres. Os depoimentos foram trabalhados pela perspectiva da Análise Temática e, considerados à luz da análise estatística, deram origem às seguintes categorias empíricas: (não) ter relação sexual independente de reprodução e (dificuldade de) acesso a meios contraceptivos; (não) expressar sua sexualidade sem violência e imposições; e (não) ter acesso à informação e educação sexual e reprodutiva.

Descritores: Direitos Sexuais e Reprodutivos; Sexualidade; Saúde da Mulher.

\section{ABSTRACT}

The sexual and reproductive rights are part of human rights supported by the Brazilian government and should be guaranteed to every citizen. However, action or omission of health professionals in the field of sexuality and reproduction may result in violation of such rights. This study aimed to identify from the reports of mothers, the violation of their human sexuality and reproduction. Descriptive study in a qualitative approach developed in July 2009 in a healthcare center in Rio de Janeiro, based on reports of twenty women. The women's speeches were analyzed by thematic content analysis and statistical analysis along resulted empirical categories (not) have sex to reproduce and independently (difficult) access to contraceptives; (not) express their sexuality without violence and charges; and (not) have access to information and sexual and reproductive education.

Descriptors: Sexual and Reproductive Rights; Sexuality; Women's Health.

\section{RESUMEN}

Los derechos sexuales y reproductivos son parte de los derechos humanos apoyados por el gobierno brasileño y, así, garantizado a todos los ciudadanos. Sin embargo, la acción o omisión de los profesionales de la salud en el ámbito de la sexualidad y la reproducción puede resultar en la violación de tales derechos. Este estudio tuvo como objetivo identificar la violación de su sexualidad y la reproducción humana, a partir de los informes de las madres. Estudio descriptivo se realizó en julio de 2009 en un centro de salud en Río de Janeiro, con enfoque cualitativo, basado en informes de veinte mujeres. Los discursos de las mujeres fueron analizados en la análisis temático de contenido y analisis estadístico, o que origino las categorías: (no) tener relaciones sexuales independientemente de la reproducción y (dificultad de) acceso a los medios contraceptivos; (no) expresar su sexualidad sin violencia y imposiciones; y (no) tener acceso a la información y educación sexual y reproductiva.

Descriptores: Derechos Sexuales y Reproductivos; Sexualidad; Salud de la Mujer.

\footnotetext{
1 Este artigo é um recorte de trabalho de conclusão de curso de graduação da Escola de Enfermagem Alfredo Pinto (EEAP), Universidade Federal do Estado do Rio de Janeiro (UNIRIO), apresentado em dezembro de 2009.

${ }^{\text {I }}$ Enfermeira. Residente em Enfermagem em Clínica Médica do Hospital Universitário Pedro Ernesto, Universidade do Estado do Rio de Janeiro. Rio de Janeiro, RJ, Brasil. E-mail: daniellie marques@oi.com.br.

II Enfermeira, Doutora em Saúde Coletiva. Professor Adjunto, EEAP, UNIRIO. Rio de Janeiro, RJ, Brasil. E-mail: adrilemosp@yahoo.com.br.
} 


\section{CONSIDERAÇÕES INICIAIS}

Ao investigar os dilemas sobre sexualidade e amamentação vivenciados por um grupo de mulheres, constatamos inúmeros conflitos relacionados à vivência sexual das entrevistadas, tanto no que se refere à primeira relação sexual quanto à sua sexualidade durante o período puerperal. Entendendo a Enfermagem como uma profissão cuja prática deve levar em conta o contexto e circunstâncias de vida do indivíduo, este artigo está pautado na perspectiva dos direitos sexuais e dos direitos reprodutivos.

O governo brasileiro está alicerçado no respeito e garantia dos direitos humanos necessários à criação e implementação de políticas voltadas para o desenvolvimento e a melhoria das condições de vida da sociedade. Nesse contexto, os direitos sexuais e reprodutivos se tornaram uma prioridade, já que visam garantir a saúde sexual e reprodutiva de homens e mulheres, tanto adultos como adolescentes ${ }^{(1)}$. Essas prerrogativas devem abranger toda e qualquer pessoa, se incluem no status de direitos humanos e devem, assim, ser reconhecidas no mesmo patamar dos direitos sociais e econômicos ${ }^{(2)}$.

Visando garantir e promover o exercício dos direitos humanos sexuais e reprodutivos (DHSR), o Ministério da Saúde apresenta diversas propostas e diretrizes que vão desde a elaboração e distribuição de manuais técnicos e cartilhas educativas sobre reprodução e sexualidade, até a ampliação da oferta de métodos anticoncepcionais reversíveis e esterilização cirúrgica voluntária no SUS (Sistema Único de Saúde). A capacitação dos profissionais de saúde da atenção básica para assistência em planejamento familiar, bem como o estabelecimento de um pacto pela redução da mortalidade materna também são focos de atenção das estratégias do Ministério da Saúde. Essas diretrizes dispõem também que as mulheres que chegam aos serviços de saúde em processo de abortamento devam ser atendidas com dignidade e tecnologia suficientes para evitar o seu adoecimento e morte ${ }^{(1)}$.

Muito embora estejam interligados em alguns momentos, os DHSR possuem distintos significados. Entende-se por direitos reprodutivos a oposição a qualquer tipo de controle coercitivo da natalidade e a qualquer imposição natalista que resulte na proibição da utilização de métodos contraceptivos. Esses conceitos não devem ser direcionados apenas e tão somente às mulheres, admitindo-se, também, as responsabilidades dos homens no processo de reprodução e regulação da fecundidade(2).
Já os direitos sexuais referem-se não só ao potencial do indivíduo expressar sua sexualidade com liberdade, sem nenhum tipo de coerção, mas também se referem ao acesso à educação sexual durante toda a vida. Tais direitos se originam nos movimentos gays e lésbicos que almejam desestigmatizar as sexualidades referidas como alternativas ${ }^{(3)}$.

A Conferência Internacional do Cairo, de 1994, e a IV Conferência sobre a Mulher de Pequim, em 1995, foram eventos essenciais para a elaboração de uma nomenclatura que melhor expressasse estes direitos ${ }^{(4)}$. Consolidou-se nestas ocasiões o entendimento de que as questões sobre sexualidade não estão necessariamente ligadas apenas à reprodução, pois devem-se considerar as possíveis sexualidades não heterossexuais e, até mesmo, individuais ${ }^{(5)}$.

Todavia, ambos os direitos são reconhecidos por diversos estudiosos como sendo um direito humano com relevância equivalente aos direitos sociais e econômicos do cidadão ${ }^{(2,6)}$. Entende-se que todo e qualquer tipo de direito, seja ele civil, político, econômico e, inclusive, cultural, deve ser respeitado. Quando um destes é violado, os outros também serão, pois é preciso garantilos de forma indivisível e compreendê-los como direitos interdependentes ${ }^{(7)}$. Entretanto, os tabus e preconceitos sobre sexualidade, até mesmo por parte dos profissionais de saúde, têm sido um grande empecilho para uma atenção de qualidade nesse aspecto( ${ }^{(6)}$. Depreende-se daí, portanto, que a ação ou omissão dos profissionais em questões do campo da sexualidade e reprodução podem resultar em violação de direitos. Nessa perspectiva, o presente estudo teve como objetivo identificar, a partir dos relatos de mulheres puérperas, a violação de seus direitos humanos sexuais e reprodutivos.

\section{METODOLOGIA}

Optou-se por uma pesquisa de natureza descritiva com abordagem qualitativa, pois o uso de tais métodos, além de permitir desvelar processos sociais referentes a grupos particulares, propicia a construção de novas abordagens, revisão e criação de novos conceitos e categorias durante a investigação ${ }^{(8)}$.

A coleta de dados foi realizada em julho de 2009 e o cenário de estudo foi um Centro Municipal de Saúde (CMS), localizado no Município do Rio de Janeiro. Os dados foram obtidos durante a permanência das mulheres no serviço, enquanto aguardavam atendimento junto aos filhos, principalmente próximo aos ambulatórios pediátricos e setor de imunização. As 
pesquisadas foram acolhidas em uma sala preparada previamente para a realização das entrevistas, de forma que a privacidade delas fosse mantida.

Para determinar o tamanho da amostra de estudo, foi utilizada uma ferramenta conceitual denominada Saturação Teórica. Esse instrumento pode ser definido como uma suspensão de inclusão de novos participantes devido à redundância ou repetição de informações, que passam a não acrescentar mais nada à pesquisa ${ }^{(9)}$. A avaliação da saturação teórica começa desde o início da coleta de dados e busca identificar o momento em que pouco de substancialmente novo é relatado, levando em consideração cada tópico abordado. Desse modo, seu uso permitiu que o grupo fosse constituído por 20 mulheres.

Atendendo as recomendações da Resolução 196/96, ${ }^{(10)}$ o trabalho de campo foi iniciado após a aprovação do Comitê de Ética em Pesquisa da Secretaria Municipal de Saúde do Rio de Janeiro sob o no 97/09, em 22 de junho de 2009. As entrevistas, do tipo semiestruturada, foram realizadas após assinatura do termo de consentimento livre e esclarecido por meio de gravação digital em uma sala reservada, e tiveram duração média de meia hora. As entrevistadas foram informadas sobre sua participação em caráter voluntário, sem compensação financeira. Ficaram sabendo também que as entrevistas não Ihes trariam prejuízos uma vez que o anonimato das informantes seria preservado. As mulheres, assim, foram identificadas, no decorrer do estudo, por indicadores numerados.

Buscando atender aos objetivos da pesquisa, durante a entrevista procurou-se seguir um roteiro elaborado previamente que continha questões como: "quando e como foi o início da sua atividade sexual?"; "a gravidez ocorreu de forma acidental?" "em quanto tempo você retomou a atividade sexual após o parto?"; e "como as relações sexuais tem sido?"; "houve orientação em relação à prática sexual?".

A partir de cada entrevista, iniciamos a leitura exaustiva por questão realizando recortes do texto em unidades de registro (palavra, tema, frase etc.) e sua distribuição em frequências absolutas e percentuais. Esse procedimento teve a finalidade de classificar e agregar os dados para a formação das categorias $^{(11)}$ que evidenciaram as violações de direitos humanos sexuais e reprodutivos para o grupo entrevistado. Surgiram três categorias empíricas: (não) ter relação sexual independente de reprodução e (dificuldade de) acesso a meios contraceptivos; (não) expressar sua sexualidade sem violência e imposições; e (não) ter acesso à informação e educação sexual e reprodutiva.

\section{ANÁLISE E DISCUSSÃo DOS DADOS}

\section{O perfil do grupo}

O grupo foi constituído por mulheres jovens, $75 \%$ delas tinham idade inferior a 30 anos. A faixa etária variou entre 18 e 44 anos e $55 \%$ das depoentes tinham dois filhos ou mais. As entrevistadas (90\%) relataram viver em um relacionamento estável. Geralmente, a união conjugal representa uma esperança de liberdade e modificação de status para muitas mulheres. Quando saem de casa e são introduzidas na vida adulta, elas adquirem uma nova função social: de filhas passam para esposas e/ou mães. Essa mudança estrutural, no entanto, nem sempre está relacionada à autonomia financeira junto à profissionalização da mulher ${ }^{(12)}$.

Paralelamente a essa constatação, observamos que a conclusão do ensino médio esteve presente em menos da metade do grupo (45\%) e somente seis mulheres (30\%) estavam inseridas no mercado de trabalho. Destaque-se, inclusive, que metade do grupo vivia com menos de um salário mínimo como renda familiar. Esse dado socioeconômico torna o universo pesquisado dependente da utilização dos serviços públicos de saúde, assim como ao acesso e orientação dos métodos contraceptivos oferecidos pelo SUS.

A maioria das entrevistadas (60\%) identificou-se como adepta da religião católica e contrária ao uso de métodos contraceptivos conhecidos como não naturais. Com relação a este tema, Duarte, um dos autores que discutem a complexidade do fenômeno da religião nas sociedades modernas, afirma que esta se estrutura em três dimensões: "a da religião" como identidade ou pertencimento; "a da religiosidade" como adesão, experiência ou crença e a "do ethos religioso" como uma disposição ética ou comportamental, associada a um universo religioso ${ }^{(13)}$.

A idade da primeira relação sexual das depoentes variou entre 13 e 28 anos. Entretanto, a maior parte vivenciou a prática sexual com idade inferior a 18 anos (55\%). Neste grupo, a idade com maior incidência ficou na casa dos 13 anos. Sete mulheres tiveram a sexarca com idade igual ou superior a 18 anos (35\%) e uma (5\%) teve sua primeira experiência aos 28 anos. Não foi possível obter resposta de duas mulheres (10\%).

Para $(85 \%)$ das entrevistadas, a primeira relação sexual foi marcada por insegurança e medos como o de sentir dor e engravidar. Além disso, para duas mulheres 
(10\%), a lembrança da primeira relação foi marcada por um ato de violência. A falta de conhecimento e acesso precário a informações resultaram na ocorrência de duas gestações na primeira vez (10\%). A maioria (85\%) vivenciou uma gestação não planejada.

\section{(Não) Ter relação sexual independente de reprodução e (dificuldade de) acesso a meios contraceptivos}

As mulheres entrevistadas não puderam separar a relação sexual da reprodução, visto que 17 informantes tiveram uma gravidez não planejada, de forma a não escolher o número de filhos, bem como o momento de tê-los. Esse fato ainda reflete as consequências históricas da atenção prestada à saúde da mulher no Brasil que, até a década de 80 , priorizava o atendimento a gravidez e amamentação. Foi só a partir de 1985 que o PAISM professou a concepção de que a saúde da mulher deveria abranger todo o seu ciclo vital e não contemplar apenas aquelas que desejavam vivenciar a maternidade. A partir daí o programa passou a incluir diversas propostas como a atenção ginecológica e o planejamento familiar ${ }^{(5)}$.

Como consequência, a Lei no 9.263/96, que trata do planejamento familiar, trouxe ao governo brasileiro, em todos os seus níveis, federal, estadual e municipal, a responsabilidade de disponibilizar orientações e métodos anticoncepcionais reconhecidamente seguros do ponto de vista científico para todas as mulheres e homens brasileiros $^{(13)}$.

Constatou-se, entretanto, a dificuldade enfrentada por algumas mulheres, que vivenciam uma sexualidade conturbada e influenciada pela insegurança, quando procuram acesso e orientação de uso correto de métodos contraceptivos. Ao serem questionadas, nove mulheres revelaram o medo de uma nova gestação, sentimento que impede o livre exercício da sexualidade.

o condom, sabemos, vem a ser um método contraceptivo eficaz, que deve estar disponível em grande parte dos serviços públicos de saúde. Ele tem dupla proteção, pois, além de prevenir uma gestação indesejada, funciona como protetor contra doenças sexualmente transmissíveis, impedindo o contato do sêmen com a vagina. Entretanto, a interferência do método na satisfação sexual do homem ou do casal representa um fator que interfere na adesão ao método ${ }^{(14)}$. Entre inúmeros aspectos relacionados ao termo "violência sexual", destaca-se também o impedimento ao uso de qualquer método contraceptivo ou negação por parte do parceiro em usar

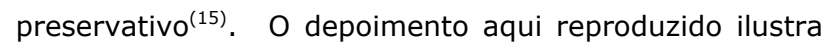

bem a situação: Eu tomo pípula mas ele também usa preservativo [...] Ele diz que só tem eu, mas eu não sei se é verdade. [...] E ele não gosta, ele não gosta reclama bem. 'Ah, você já tem duas meninas' (Entrevistada 1).

A dificuldade de acesso à laqueadura tubária também surgiu no depoimento de duas entrevistadas. Uma delas, aos 33 anos, cuidava do quarto filho, e a outra, aos 44 anos, conduzia os dois filhos, o último deles com apenas três meses. Este método (laqueadura tubária) pode ser escolhido por mulheres com capacidade civil plena e maiores de 25 anos de idade ou, pelo menos, dois filhos vivos, com um prazo mínino de 60 dias entre a manifestação da vontade e o ato cirúrgico, com aconselhamento multidisciplinar, visando desencorajar a esterilização precoce ${ }^{(13)}$.

Além da dificuldade de acesso ao método, evidenciou-se uma informação equivocada sobre o direito de esterilização voluntária, o que nos permitiu inferir que a atuação dos profissionais de saúde ainda está distanciada da perspectiva de promoção dos direitos humanos sexuais e reprodutivos da mulher. O relato abaixo traz à tona ao equívoco: $A$ ligadura é mais para quem tem mais de três cesáreas, aí a quarta se torna perigosa, aí já já faz o parto e já liga, pra quem não tem passagem. Mas a gente que tem parto normal, a gente não tem ligadura (Entrevista 2).

No ano de 2003, o SUS contava com apenas 431 serviços credenciados para a realização da esterilização cirúrgica. Estabeleceu-se, então, uma meta para que o número de serviços habilitados para tal procedimento aumentasse em 50\%, entre os anos de 2004 e 2007, em conformidade com a Lei n.0 9.263/96. Entretanto, tal benefício pareceu não ter alcançado o grupo de entrevistadas que desejavam o método de esterilização feminina ${ }^{(16)}$.

O acesso a meios contraceptivos se torna essencial para a mulher após o parto. A razão é simples: Os curtos intervalos entre as gestações estão relacionados a fatores que contribuem para a mortalidade materna, neonatal e infantil. Quando os intervalos são inferiores há 18 meses, há maior probabilidade de prematuridade, crianças com baixo peso ao nascer, subnutrição, paralisia cerebral e até desordens menstruais em crianças do sexo feminino. Com relação à mulher, acompanha-se também um aumento da mortalidade devido à endometrite puerperal, anemia, perda sanguínea durante o terceiro trimestre e ruptura prematura de membranas ${ }^{(14)}$.

Portanto, a não utilização ou o uso inadequado dos meios contraceptivos contribuem para o aumento de gestações indesejadas que, por sua vez, acabam levando 
as mulheres a cometerem o aborto considerado ilegal no Brasil. Qual seja aquele feito por meio de serviços ditos como clandestinos. A conseqüência é bem conhecida: o aumento da mortalidade materna advinda das hemorragias, infecções e perfurações uterinas ${ }^{(17)}$.

\section{(Não) Expressar sua sexualidade sem violência e imposições}

No que se refere à livre expressão da sexualidade sem nenhum tipo de coerção, observou-se que duas mulheres tiveram esse direito violado: uma foi violentada sexualmente durante a sexarca e outra era forçada a manter relações sexuais. Um dos depoimentos é impressionante: Não foi bem assim o que eu queria não [sobre a sexarca], porque foi quando eu tive aquele negócio com bandido. Eu fui agarrada a força na verdade. Mas não foi porque eu quis não. Treze anos (Entrevistada 3).

Entre os diversos danos infligidos pela agressão sexual, podemos citar aqui os que afetam a saúde mental como a ansiedade, a depressão e até o suicídio. Sabe-se que a agressão sexual está relacionada a lesões, gravidez indesejada, disfunções sexuais e DST. Essa violência provoca repercussões no estado psicológico da mulher violentada ${ }^{(16)}$ e, portanto, não deve apenas ser olhada pelo prisma jurídico. A questão deve ser abordada também por outros focos relacionados ao bem-estar físico e mental da mulher agredida.

Existem, entretanto, muitos tabus a serem superados quando o tema é a violência sexual. A legislação brasileira só permite a realização do aborto, dito terapêutico, naquelas condições em que há risco de morte materna ou então quando a gestação resulta de um estupro. Neste último caso, devido à dependência de uma autorização judicial, a demora habitual dos processos geralmente inviabiliza a intervenção em tempo hábil ${ }^{(17)}$.

A violência sexual é um assunto muito delicado quando tratado diretamente com as mulheres, já que, geralmente, os autores da agressão são os próprios parceiros, maridos ou namorados. Assim é que a mulher, ou por medo de sofrer represálias, quando o autor é conhecido, ou por sentir-se humilhada ou culpada, resolve silenciar e reprimir suas angústias. Este tipo de comportamento persiste porque no contexto social - e até mesmo entre os profissionais de saúde que prestam atendimento a essas mulheres nos serviços de emergência - permanece o entendimento de que a mulher é culpada pela violência sexual sofrida ${ }^{(16)}$.
No caso do grupo entrevistado - formado por puérperas - é preciso considerar que a adaptação à maternidade pode trazer dificuldades na vida sexual do casal, sobretudo com relação à diminuição da libido por alterações hormonais que ocorrem após o parto ${ }^{(18)}$. Isso faz com que essas mulheres apresentem vulnerabilidades relacionadas à violência sexual praticada pelo próprio parceiro. Geralmente ela (a mulher) aceita a violação porque considera ser uma obrigação sua atender a satisfação sexual do seu cônjuge.

Outro fator observado no depoimento de uma entrevistada foi certo tipo de coerção que ocorre no processo de escolha do seu parceiro sexual. A depoente revelou ter sido influenciada por um familiar que, com base na percepção da moralidade da mulher associada à valorização da virgindade, impôs o argumento de que se ela já havia mantido relações sexuais, deveria, a partir daquele momento, estabelecer uma união estável com o parceiro. Reproduzimos aqui seu depoimento: Ai minha tia perguntou 'você é mulher dele?' e eu falei assim 'não, não moro com ele pra ser mulher dele', mas ela falou 'não, você se perdeu com ele, você, agora você é mulher dele' (Entrevistada 16).

O episódio relatado reflete que o exercício da sexualidade se dá de forma diferenciada entre os gêneros: enquanto os rapazes são incentivados às relações sexuais para alcançarem maior experiência, o gênero feminino ainda vivencia a supervalorização da virgindade, do recato e do casamento, mesmo que em menor proporção do que nas décadas anteriores ${ }^{(19)}$.

\section{(Não) Ter Acesso à informação e educação sexual e reprodutiva}

Para duas mulheres entrevistadas o início da atividade sexual foi marcado pela falta de informação, o que, inclusive, acabou resultando em gravidez não planejada na primeira relação. Uma delas assim descreveu sua experiência: Na primeira relação que eu tive, passaram-se duas ou três semanas e eu comecei a passar mal e fui no médico - tá grávida. Que isso?! Foi um choque pra mim depois disso. Não sabia nem o que era camisinha (Entrevista 8).

Uma depoente que se considera praticante do catolicismo e que viveu, até os 13 anos, em um colégio interno, também relatou ter tido a primeira experiência sem receber nenhum tipo de esclarecimento prévio da família. A entrevistada disse que também não recebeu nenhuma informação da instituição de ensino e moradia que a abrigava. Essa lacuna, responsável direta pela 
falta de informação e educação sexual e reprodutiva, também esteve presente no relato de outras três mulheres.

Independente da maneira como a sexualidade foi abordada na infância e adolescência do indivíduo, a formação escolar não deve omitir o processo da sexualidade humana. Prestando aos estudantes as informações adequadas, o sistema educacional irá seguramente colaborar com o autoconhecimento necessário ao desenvolvimento pleno de seus usuários. $\mathrm{Na}$ tentativa de minimizar as carências ainda encontradas nos estabelecimentos de ensino - naquilo que diz respeito à sexualidade na adolescência - foi criado, em 2003, o Programa Saúde e Prevenção nas Escolas. A iniciativa foi implantada em vários municípios, destacando-se, entre eles, o Rio de Janeiro. Este programa, que resultou de uma parceria entre o Ministério da Saúde e o Ministério da Educação, tinha como principal objetivo diminuir as vulnerabilidades dos adolescentes às DST e a gravidez indesejada. A ênfase foi a promoção da saúde por meio da capacitação de professores do ensino médio e fundamental ${ }^{(1)}$.

A saúde sexual e reprodutiva da população adolescente, principalmente na faixa dos 10 aos 15 anos, deve ser alvo da atenção dos profissionais de saúde, uma vez que as expectativas familiares e sociais sobre essa faixa etária geralmente não incluem o aspecto da maternidade ou paternidade. E essa omissão, sabemos, pode acarretar consequências indesejáveis para os adolescentes $^{(1)}$.

Historicamente, a sexualidade foi reprimida na sociedade, sobretudo pela educação religiosa. Esta última ficou marcada por sua posição castradora, repressora quanto aos toques, verbalizações. A repressão também restringiu a exteriorização de sentimentos relacionados ao amor e ao sexo. Esta visão medieval ainda repercute socialmente e faz com que a sexualidade seja um tema bastante estigmatizado pela nossa sociedade. Como consequência, a educação sexual desde a infância ainda é um assunto reprimido e acarreta diversos dilemas que se referem ao desenvolvimento e comportamento sexual dos indivíduos ${ }^{(1)}$.

A questão da saúde sexual e reprodutiva, no entanto, está incluída nas diretrizes do sistema educacional através dos parâmetros curriculares. Estes últimos estabelecem a inclusão de um tópico especial sobre orientação sexual, e, no âmbito do setor da saúde, incluem programas e serviços de atenção integral à saúde do adolescente, privilegiando a orientação sexual com vistas à prevenção da gravidez precoce e das DST/AIDS.

A saúde e a sexualidade são aspectos que se relacionam e constituem um direito humano social. Logo, o enfermeiro, na qualidade de profissional de saúde, deve colaborar para que a mulher seja capacitada para participar ativamente do seu processo de saúde-doença. Essa participação deve estar centrada na tomada de decisões e no respeito aos seus direitos sexuais e reprodutivos. A saúde é dever do Estado e a atenção à saúde é realizada pelos profissionais; logo, os representantes do Estado devem incorporar em suas práticas a promoção dos $\operatorname{DHSR}^{(15)}$.

\section{CONSIDERAÇÕES FINAIS}

Ao longo do levantamento aqui delineado identificamos que as entrevistadas, durante a sexarca, enfrentaram uma série de dificuldades comuns. Uma delas foi a dificuldade de poder expressar sua sexualidade sem violência ou imposições. Outra foi a privação de escolha do parceiro sexual e a falta de informações, meios e métodos para ter ou não filhos. Constatou-se, assim, que as mulheres sofreram violações desde a primeira relação sexual - tanto no que se refere aos seus direitos sexuais quanto aos reprodutivos.

Essa violação parece se perpetuar ao longo da vivência sexual da mulher, dificultando a separação da vida sexual da reprodução, fenômeno que em alguns casos provoca gestações acidentais. No puerpério, percebeu-se que as entrevistadas tinham dificuldades de acesso a meios contraceptivos. As consequências daí advindas são bem conhecidas: as relações sexuais se tornam uma espécie de obrigação para a mulher e elas procuram atender apenas às necessidades do seu parceiro.

Portanto, é necessário que os enfermeiros que prestam assistência a mulher, principalmente durante o período puerperal, estejam atentos a questões que envolvem a sexualidade. Deve-se entender que a mulher tem o direito de expressar e gozar de sua sexualidade sem nenhum tipo de coerção ou opressão. E a melhor forma de prestar uma assistência de qualidade é garantir o exercício dos direitos sexuais e dos direitos reprodutivos.

A saúde da mulher deve ser compreendida como o resultado de um amplo espectro de fatores que, assim como o pleno exercício de sua sexualidade, estão relacionados com a sua qualidade de vida. Nesse contexto, o estudo aqui desenvolvido sugere um 
repensar sobre a prática profissional em saúde. Essa reformulação parte do princípio segundo o qual é necessário compreender os elementos determinantes da experiência vivenciada pela mulher. A partir daí será construído um conjunto de metas que auxiliem a mulher na tomada de decisão sobre sua sexualidade. Esta prática também deverá incorporar e considerar aspectos

\section{REFERÊNCIAS}

1. Departamento de Ações, Programáticas Estratégicas Ministério da Saúde. Direitos sexuais e direitos reprodutivos: uma prioridade do governo [Internet]. Brasília (Brasil): Ministério da Saúde; 2005 [cited 2011 set 30]. Available from: http://sistemas.aids.gov.br/feminizacao/index.php?q=system/file s/cartilha2.pdf.

2. Petchesky RP. Rights and needs: rethinking the connections in debates over reproductive and sexual rights. Health Hum Rights. 2000;4(2):17-29.

3. Lemos A. Grupos educativos em contracepção: narrativas e práticas de enfermeiras. Cogitare Enferm. [Internet]. 2011 [cited 2011 set 30];16(1):36-42. Available from: http://ojs.c3sl.ufpr.br/ojs2/index.php/cogitare/article/view/2110 9/13935.

4. Vianna A. Direitos e políticas sexuais no Brasil: mapeamento e diagnóstico. Rio de Janeiro: CEPESC; 2004.

5. Corrêa S, Jannuzzi PM, Alves JED. Direitos e saúde sexual e reprodutiva: marco teórico-conceitual e sistema de indicadores [Internet]. Campinas: Associação Brasileira de Estudos Populacionais; 2003 [cited 2011 set 30]. Available from: http://www.abep.org.br/fotos/Dir Sau Rep.pdf.

6. Álvila MB. Direitos sexuais e reprodutivos: desafios para as políticas de saúde. Cad Saude Publica [Internet]. 2003 [cited 2011 set 30];19 Suppl 2:S465-9. Available from: http://www.scielo.br/pdf/csp/v19s2/a27v19s2.pdf.

7. Pioversan F. Os Direitos Reprodutivos como Direitos Humanos. In: Buglione S, organizadora. Reprodução e Sexualidade: Uma questão de justiça. Porto Alegre: Sergio Antonio Fabris Editor e Themis - Assessoria Jurídica e Estudos de Gênero; 2002.

8. Minayo MCS. O desafio do conhecimento: pesquisa qualitativa em saúde. São Paulo: Hucitec; 2007.

9. Fontanella BJB, Ricas J, Turato ER. Amostragem por saturação em pesquisas qualitativas em saúde: contribuições teóricas. Cad Saude Publica [Internet]. 2008 [cited 2011 set 30];24(1):17-27. Available from: http://www.scielo.br/pdf/csp/v24n1/02.pdf.

10. Ministério da Saúde; Conselho Nacional de Saúde. Resolução No 196/96 - Normas regulamentadoras de pesquisa envolvendo seres humanos. Brasília (Brasil): Ministério da Saúde; 1996.

11. Bardin L. Análise de conteúdo. Lisboa: Edições 70; 2006.

12. Duarte LFD. Ethos privado e justificação religiosa: negociações da reprodução na sociedade brasileira. In: Heilborn ML, Duarte LFD, Peixoto C, Barros ML, organizadores. Sexualidade, família e ethos religioso. Rio de Janeiro: Garamond; 2005.

13. Congresso Nacional. Lei no 9.263/96. Trata do planejamento familiar, estabelece penalidades e dá outras providências. Brasília (Brasil): Congresso Nacional; 1996.

14. Vieira CS, Brito MB, Yazlle MEHD. Contracepção no puerpério. Rev Bras Ginecol Obstet [Internet]. 2008 [cited 2011 set 30];30(9):470-9. Available from: http://www.scielo.br/pdf/rbgo/v30n9/v30n9a08.pdf.

15. Galli B, Vidaurre $M$. Violência sexual e direitos humanos: fortalecendo a rede e promovendo os direitos sexuais e reprodutivos de adolescentes [Internet]. Rio de Janeiro: Advocaci/Ipas Brasil; 2004 [cited 2010 set 30]. Available from: http://www.ipas.org/Publications/asset upload file131 3618.pdf 16. Souza CM, Adesse L, organizadoras. Violência Sexual no Brasil: perspectivas e desafios [Internet]. Brasília: Secretaria da masculinidade e a participação do homem como sujeito dos DHSR.

Valorizar a percepção da mulher no que diz respeito à sua sexualidade fortalece a idéia de proteção aos direitos sexuais e reprodutivos. E estes últimos, sabemos, representam uma conquista da sociedade. Sem eles não há o pleno exercício dos próprios direitos humanos.

Especial de Políticas para as Mulheres; 2005[cited 2010 set 30]. Available from: http://www.sepm.gov.br/publicacoesteste/publicacoes/2005/violenciasexual.pdf.

17. Teixeira SVB, Rocha CR, Moraes DSD, Marques DM, Villar ASE. Educação em saúde: a influência do perfil sócio-econômicocultural das gestantes. Rev. enferm. UFPE on line. [internet]. 2010 [cited 2011 set 30];4(1):133-41. Available from: http://www.ufpe.br/revistaenfermagem/index.php/revista/article /view/546/pdf_303.

18. Marques DM, Lemos A. Sexualidade e amamentação: dilemas da mulher/mãe. Rev. enferm. UFPE on line. [Internet]. 2010 [cited 2011 set 30]; 4(1):622-30. Available from: http://www.ufpe.br/revistaenfermagem/index.php/revista/article /viewFile/806/pdf 50.

19. Pereira AL. A sexualidade no cuidar: experiências conflitantes de discentes de enfermagem. Rev. de Pesq.: cuidado é fundamental Online [Internet]. 2009 [cited 2011 set 30];1(2):326-34. Available from: http://www.seer.unirio.br/index.php/cuidadofundamental/article/ view/383/375.

Artigo recebido em 24.04.2010.

Aprovado para publicação em 29.08.2011.

Artigo publicado em 30.09.2011. 